\title{
PENGETAHUAN PENTADBIR SEKOLAH RENDAH TENTANG ASPEK PERUNDANGAN DALAM PENDIDIKAN
}

\author{
LOKMAN MOHD TAHIR ${ }^{1 *}$, MOHD ANUAR ABD RAHMAN ${ }^{2} \&$ \\ ROSLAN PONGSU@BABA ${ }^{3}$
}

\begin{abstract}
Abstrak. Perundangan merupakan elemen penting kepada sesebuah sekolah memandangkan operasi sebuah sekolah kerap melibatkan aspek perundangan. Sehubungan itu, kajian ini dirangka khusus untuk menjawab persoalan sama ada para pentadbir sekolah berpengetahuan tentang aspek perundangan dalam pendidikan. Di samping itu, kajian ini juga cuba meneliti amalannya di sekolah. Sampel kajian terdiri daripada 87 orang pentadbir di 20 buah sekolah rendah terdiri daripada Guru Besar, Guru Penolong Kanan 1, Guru Penolong Kanan Hal Ehwal Murid, Guru Penolong Kanan Kokurikulum, dan Guru Penolong Kanan Petang. Data kajian ini dianalisis dengan menggunakan kaedah kekerapan, peratusan dan min serta pengujian statistik Ujian-t, ANOVA Sehala. Secara umum, hasil kajian menunjukkan bahawa keseluruhannya pentadbir memiliki pengetahuan yang tinggi mengenai peraturan dan undang-undang pendidikan dan sentiasa mematuhi garis panduan dan prosedur pengurusan organisasi sekolah. Di samping itu, pentadbir juga didapati sentiasa merujuk kepada akta dan undang-undang pendidikan semasa mengurus sekolah. Namun demikian, pentadbir sekolah sendiri mengakui bahawa mereka kurang diberi pendedahan melalui latihan dan kursus mengenai undang-undang pendidikan. Beberapa cadangan dikemukakan untuk meningkatkan kemampuan pentadbir sekolah dalam bidang perundangan pendidikan.
\end{abstract}

Kata kunci: Pentadbir sekolah rendah; perundangan pendidikan; literasi undang-undang

\begin{abstract}
Legislation is considered as important element for school organization with the assumption that school operations involved law element. This study was conducted to investigate the primary school administrators' knowledge about the legislation in education. In addition, this study also identified differences significant of demographic factors, school administrators, legal knowledge, which involves schools and the relationship between demographic factors with knowledge of the legalization. Sample for this study were 87 primary school administrators of 20 schools which were school's headmasters, Senior Assistant (Administration), Senior Assistant (Student Affairs); Senior Assistant (Co-curriculum) and Senior Assistant (Evening Session). Data were analyzed using descriptive and inferential statistics such as frequencies, percentages and mean scores, t-test, one-way ANOVA. Results showed that headmaster have high level of knowledge related the produces, regulation and law in education. In addition, primary school administrators frequently used educational law and legislation as their main source while leading and managing the school. However, school administrators also admitted
\end{abstract}

Fakulti Pendidikan, Universiti Teknologi Malaysia, 81310 UTM Johor Bahru

Corresponding author: p-lokman@utm.my 
they were less exposed to courses and workshop related to education legislation. Suggestions were also forwarded to enhance the primary school capabilities related to legislation in education.

Keywords: Primary school administrators; educational legislation; legal literacy

\subsection{PENGENALAN}

Sistem pendidikan pada masa kini amat kompleks iaitu sering berubah seiring dan pola perkembangan masyarakat kini yang peka dan berminat tentang perubahan dalam sistem pendidikan. Peningkatan kesedaran masyarakat ini sebenarnya hasil impak daripada peningkatan ilmu pengetahuan, kemajuan sosioekonomi, kepesatan bidang teknologi maklumat dan komputer seperti media elektronik dan internet. Akibatnya, ibu bapa dan para pelajar kini semakin jelas terhadap limitasi, peranan dan tanggungjawab guru dan pentadbir di sekolah. Oleh itu, sekolah kini tidak dapat 'lari' daripada membicarakan persoalan undang-undang kerana segala urusan dan prosedur di sekolah amat berkait dengan undang-undang seperti kontrak antara guru dengan pelajar, keselamatan pelajar, undang-undang tort dan isu undang-undang yang lain yang memberi impak kepada operasi sekolah secara keseluruhan (Lunenburg \& Irby, 2006).

Berkait dengan kepekaan ibu bapa tentang undang-undang dan tanggungjawab pendidik, bidang perguruan kini dilihat semakin terdedah kepada pelbagai jenis cabaran dan kaum guru terutama pentadbir sekolah mula menjadi sasaran tindakan undang-undang oleh pihak mahkamah. Kecenderungan masyarakat kini yang gemar mengambil tindakan mahkamah terhadap guru dilihat sebagai senario yang semakin berleluasa dalam bidang pendidikan di Malaysia. Natijahnya, golongan guru merasakan bahawa profesion pendidikan sebagai suatu profesion yang mudah terdedah kepada pelbagai risiko dan liabiliti kerana bidang pendidikan merupakan bidang perkhidmatan yang berurusan dengan manusia khususnya para pelajar (Sametz, McLouglin \& Streib, 1983).

\subsection{AKAUNTIBILITI PENTADBIR SEKOLAH DALAM BIDANG PERUNDANGAN}

Dunia pendidikan semakin hari semakin bertambah kompleks. Hampir setiap hari terdapat berita berkaitan pendidikan sama ada daripada aspek disiplin atau 
salah laku, deraan, akademik, ko-kurikulum telah disiarkan di media. Hal ini adalah kerana ramai pihak yang berminat dan mahu terlibat secara langsung ataupun tidak langsung dalam dunia pendidikan walaupun mereka sebenarnya tidak mempunyai sebarang kepentingan (Stewart, 2005). Namun demikian, aspek perundangan dalam pendidikan masih kurang diberi perhatian oleh pemimpin sekolah (Fischer et al., 1981; Fischer et al., 2003; McDanieal, 1979; Stewart, 1998) dan para pendidik walaupun pengetahuan tentang perundangan amat berkait rapat dengan operasi harian sesebuah sekolah. Tindakan yang diambil oleh guru dan pihak sekolah sebenarnya perlu selari dan tidak bercanggah dengan undang-undang yang telah diwartakan dalam akta dan peraturan yang berkait dengan undang-uandang (Reglin, 1990, Ramsay \& Shorten, 1996; Williams, 1994). Beberapa kajian di Amerika Syarikat, Australia dan New Zealand (Sorenson \& Chapman, 1980; Kigin, 1983; Dunklee, 1983; Pell, 1994) telah mendapati bahawa kurang minat untuk mendalami bidang perundangan dalam pendidikan oleh pemimpin sekolah berpunca daripada beberapa faktor iaitu (a) pemimpin dan guru dilatih sebagai pendidik dan bukan sebagai pengamal undang-undang, (b) kurang minat dan kurangnya pemahaman tentang aspek perundangan menjadikan para pendidik tidak berminat dalam aspek perundangan walaupun pengurusan sesebuah institusi sekolah sebenarnya berkait dengan aspek undang-undang iaitu elemen tanggungjawab, kecuaian, langkah berjaga-jaga oleh pemimpin sekolah.

Di sekolah, pihak pentadbir sekolah dan guru merupakan penjawat yang paling kerap terdedah kepada dakwaan (litigation) atas pelbagai tuduhan seperti kegagalan melaksanakan tanggungjawab, kecuaian, penyalahgunaan kuasa dan penyelewengan yang mungkin berlaku (Tie Fatt Hee, 2002; 2004). Berdasarkan punca-punca dakwaan tersebut, kecuaian merupakan bidang yang amat luas dan pihak sekolah merupakan pihak yang paling berkemungkinan didakwa atas tuduhan kecuaian. Elemen kecuaian sebenarnya berkait dengan aspek kegagalan memenuhi "kewajipan berjaga-jaga" (duty of care), kegagalan melaksanakan tanggungjawab, dan kegagalan mematuhi arahan serta peraturan boleh mengakibatkan pihak sekolah menghadapi dakwaan sivil atau pun jenayah (sivil or criminal suit) (Ramsay \& Shorten, 1996). Tindakan mahkamah yang diambil terhadap pihak sekolah sudah tentu akan memberi kesan yang serius kepada sekolah (Tie Fatt Hee, 2002). Oleh demikian, pentadbir sekolah amat perlu melengkapkan diri dengan pengetahuan mengenai hak perundangan dan tanggungjawab mereka ketika di sekolah. Pengetahuan dalam bidang undangundang pendidikan oleh guru dan pentadbir sekolah dianggap sudah memadai 
sebagai suatu tindakan berjaga-jaga (Stewart, 1998; Stewart 2005) bagi mengelakkan mereka daripada dikenakan dakwaan di mahkamah.

Di samping itu, pihak sekolah boleh didakwa ke mahkamah termasuk kecuaian (negligence), kegagalan melaksanakan tanggungjawab, kegagalan menepati kehendak undang-undang (akta dan peraturan-peraturan pendidikan), penyalahgunaan kuasa dan penyelewengan. Kecuaian (negligence) dikaitkan dengan "kewajipan berjaga-jaga" (duty of care). Semua sekolah mempunyai kewajipan berjaga-jaga (owe a duty of care) kepada pekerja-pekerja dan anak-anak muridnya. Hal ini bermakna pentadbir sekolah perlu melindungi kesihatan, keselamatan, dan kebajikan guru-guru dan murid-muridnya iaitu perlu mengambil langkah-langkah untuk mengenal pasti dan seterusnya mengurangkan risiko-risiko yang boleh dijangka (forseeable risks) daripada berlaku (Waring \& Glendon, 1998). Perbuatan seseorang (defenden) boleh dikatakan cuai oleh mahkamah apabila ketiga-tiga syarat berikut dipenuhi iaitu: (a) Defendan mempunyai tanggungjawab "kewajipan berjaga-jaga" (requirement to exercise duty of care) terhadap plaintif, (b) Defenden telah tidak melakukan "kewajipan berjaga-berjaga" (failure to exercise duty of care), (c)Plaintif mengalami kecederaan atau kerugian (damage has occurred) akibat daripada kegagalan defendan melakukan kewajipannya ( Mohd Ismail Othman, 2004: Tie Fatt Hee 2002; Tie Fatt Hee, 2004).Rentetan daripada senario tersebut, Kementerian Pelajaran Malaysia pun mengedarkan Surat Pekeliling Ikhtisas Bil. 8/1983 - Mengenakan Hukuman Biasa Terhadap Murid murid Yang Melakukan Perbuatan Salah Laku Yang Tidak Dinyatakan Dalam Peraturan Peraturan Pelajaran. Seterusnya, pihak Kementerian Pelajaran mengeluarkan pula Surat Pekeliling Ikhtisas Bil. 7/1995 - Tatacara Mengenakan Tindakan dan Hukuman Terhadap Pelajar Pelajar Sekolah (Surat Pekeliling Ikhtisas, Kementerian Pelajaran Malaysia, 1995; 1983).

Bagi meminimumkan kemungkinan pihak sekolah didakwa kerana kecuaian, pentadbir sekolah perlu memahami dan menguasai aspek perundangan di sekolah terutama yang berakit dengan kecuaian dan serta tingkah laku dan elemen pengurusan di sekolah untuk mengelakkan institusi sekolah daripada dikenakan tindakan mahkamah. Secara amnya, jika pentadbir sekolah perlu dan harus mematuhi segala arahan serta peraturan semasa menjalankan tugas-tugas harian dan melaksanakan "kewajipan berjaga-jaga", maka warga sekolah iaitu, guru, pelajar akan merasa selamat dan dilindungi dari sebarang dakwaan dan tindakan mahkamah yang mungkin berlaku (Waring \& Glendon, 1998). Malah Wood dan Huffman (1999) yang dipetik dalam Tie Fatt Hee (2004) dan Stewart (1998; 2005) 
telah menyenaraikan beberapa strategi yang perlu dilaksanakan oleh pihak sekolah iaitu: (a) membina satu pelan perkembangan staf yang menitikberatkan pelan pengurusan keselamatan dan risiko di sekolah serta bekerjasama secara dua hala dengan masyarakat tempatan, polis mahupun bomba, (b) latihan kepada pihak pengurusan dan kepimpinan sekolah perlu dimantapkan lagi dengan membina satu pasukan pengurusan keselamatan, (c) mengintegrasi polisi keselamatan sekolah sebagai satu budaya yang perlu diamalkan dengan penuh penghayatan oleh setiap warga sekolah, (d) membina satu pasukan intervensi disiplin yang dapat memantau perkembangan gang, kongsi gelap serta situasi ganas yang berlaku di sekolah, (e) membina perhubungan yang mantap dengan ibu bapa serta menitikberatkan program keibu bapaan di sekolah (f) mengenal pasti, peka akan situasi yang berisiko, tanda-tanda awal akan keganasan supaya mudah disusun strategi dan langkah pencegahan.

Dalam konteks keselamatan di sekolah yang berkait dengan struktur fizikal sekolah pula, pentadbir sekolah perlu memastikan premis sekolah sentiasa selamat untuk digunakan oleh semua pihak yang mempunyai hak menggunakannya yang tergolong dalam aspek pengurusan risiko di sekolah (Minor \& Minor, 1991). Dalam konteks ini, peranan sebagai occupier's liability perlu dilaksanakan oleh pentadbir sekolah iaitu konsep tanggungan pengetua iaitu penghasilan bentuk kawalan ke atas suatu premis atau kawasan sekolah. Oleh itu, pentadbir sekolah perlu sentiasa memastikan keadaan fizikal sekolah sentiasa selamat, kerap diselenggarakan dengan baik kerana segala kerosakan dan ketidaksempurnaan yang terdapat pada kemudahan fizikal yang dapat mengugat keselamatan pelajar serta sesiapa yang memasuki kawasan sekolah (Tie Fatt Hee, 2002; Schimmel et al., 2008; Normazli, 2004). Permuth (1998) pula menegaskan bahawa selaku pengetua beberapa elemen perlu dipastikan iaitu: (a) memastikan bahawa setiap aktiviti di sekolah perlu diselia dengan rapi dan terperinci oleh guru: (b) langkah berjaga-jaga dan pelan keselamatan perlu dikemaskini dengan kerap terutamanya berkait dengan aktiviti-aktiviti luaran sekolah seperti pendidikan jasmani dan ko-kurikulum: (c) mengambil langkah pencegahan yang drastik kepada elemen yang akan mengundang kepada aspek kecuaian; (d) melibatkan ibu bapa dan pihak luar dalam membantu mempertingkatkan keselamatan di sekolah, dan (e) mengenal pasti risiko-risiko yang menjurus kepada masalah kepada sekolah. Di samping itu, pentadbir sekolah juga dikehendaki memastikan bilik-bilik darjah memenuhi syarat-syarat keselamatan iaitu spesifikasi keluasan, tingkap, pengudaraan, ketinggian siling, dan ruang yang mencukupi untuk setiap 
murid, cahaya yang cukup terang, bilangan maksimum murid yang dibenarkan dalam setiap bilik dan lain-lain prasarana perlu dipantau oleh pemimpin sekolah. Maka, pengetua dan Guru Besar perlu memastikan peraturan tersebut dipatuhi untuk mengelak dakwaan kerana kecuaian.

Berkait dengan aspek penyeliaan pula, pentadbir sekolah perlu memastikan bahawa guru-guru perlu membuat penyeliaan yang munasabah ke atas tingkah laku murid-murid di bawah jagaannya di dalam kelas sewaktu aktiviti pengajaran dan pembelajaran berjalan. Kegagalan guru berbuat demikian boleh menyebabkan beliau didakwa jika murid tercedera di dalam kelas akibat kecuaian guru. Bagi Schimmel et al., (2008), guru boleh didakwa jika gagal melaksanakan beberapa berikut: (a) guru perlu berhati-hati untuk mengelakkan pelajar daripada tercedera, (b) guru gagal menjaga pelajar di bawah seliannya dengan baik, (c) kecuaian guru telah menyebabkan kecederaan (d) kecederaan tersebut akan menyebabkan kecacatan. Berdasarkan akauntibiliti yang perlu dipikul atau diurus oleh pentadbir sekolah yang berkait dengan undang-undang dalam pendidikan, maka satu kajian terperinci tentang beberapa aspek dalam perundangan seperti latihan, pemahaman, sumber rujukan dalam perundangan dijadikan asas kepada kapasiti pentadbir sekolah rendah dalam bidang perundangan pendidikan.

\subsection{OBJEKTIF KAJIAN}

Kajian ini secara khususnya ingin meneliti kemahiran, pendedahan dan latihan yang mencukupi, sumber-sumber rujukan perundangan di samping perlindungan yang disediakan oleh pihak penggubal dasar. Oleh itu, beberapa objektif telah dibina iaitu:

(a) Mengenal pasti sama ada pentadbir sekolah (Guru Besar, GPK Pentadbiran, GPK HEM, GPK Kokurikulum, dan GPK Petang) mempunyai pengetahuan dan kemahiran tentang undang-undang dan prosedur pendidikan.

(b) Mengenal pasti kekerapan pentadbir sekolah membuat rujukan tentang undang-undang pendidikan daripada sumber-sumber rujukan yang sesuai. 
(c) Mengenal pasti sama ada pentadbir sekolah mendapat latihan dan kursus tentang undang-undang dan prosedur pendidikan yang secukupnya.

(d) Mengenalpasti tahap perlindungan dan kemudahan perundangan yang boleh diperolehi oleh pentadbir sekolah.

(e) Mengenal pasti perbezaan yang signifikan berdasarkan faktor-faktor demografi pentadbir sekolah tentang pengetahuan perundangan pendidikan.

\subsection{METODOLOGI}

Sampel untuk kajian terdiri daripada pentadbir sekolah rendah daerah iaitu terdiri daripada Guru Besar, Guru Penolong Kanan (Pentadbiran), Guru Penolong Kanan (Hal Ehwal Murid), Guru Penolong Kanan (Ko-kurikulum), dan Guru Penolong Kanan (Petang) yang berkhidmat di 20 buah sekolah rendah iaitu Sekolah Kebangsaan, Sekolah Jenis Kebangsaan (Cina), dan Sekolah Jenis Kebangsaan (Tamil) yang dipilih secara rawak oleh penyelidik. Instrumen kajian menggunakan skala likert lima mata iaitu 5 untuk sangat berseuju, skala 4 - untuk setuju, skala 3 - untuk tidak pasti, skala 2 untuk tidak bersetuju dan skala 1 untuk sangat tidak bersetuju. Instrumen kajian ini juga mengumpul maklumat berkaitan dengan ciri demografi pentadbir sekolah berkenaan jantina, umur, lokasi sekolah, kelulusan akademik, kategori perkhidmatan, gred jawatan, jawatan dan pengalaman dalam jawatan. Instrumen kajian mengandungi 60 item iaitu 15 item tentang pengetahuan dan ilmu pentadbir sekolah mengenai prosedur dan undangundang pendidikan; 15 item tentang kebolehan pentadbir membuat rujukan daripada sumber-sumber undang-undang pendidikan, 15 item tentang latihan dan kursus yang pernah dihadiri oleh pentadbir sekolah berkaitan akta dan undangundang pendidikan, 15 item pula tentang tahap perlindungan dan kemudahan yang diterima oleh pentadbir sekolah seperti dalam Jadual 1. 
Jadual 1 Taburan item dan nilai kebolehpercayaan alfa

\begin{tabular}{lcc}
\hline \multicolumn{1}{c}{ Dimensi Item Kajian } & Jumlah Item & $\begin{array}{c}\text { Nilai } \\
\text { Alfa } \\
\text { Rintis }\end{array}$ \\
\hline $\begin{array}{l}\text { Pengetahuan mengenai prosedur } \\
\text { dan undang-undang pendidikan }\end{array}$ & 15 item & 0.705 \\
$\begin{array}{l}\text { Kebolehan pentadbir membuat rujukan } \\
\text { daripada sumber-sumber undang-undang } \\
\text { pendidikan }\end{array}$ & 15 item & 0.841 \\
$\begin{array}{l}\text { Latihan dan kursus yang pernah dihadiri } \\
\text { berkenaan akta dan undang-undang pendidikan }\end{array}$ & 15 item \\
$\begin{array}{l}\text { Tahap perlindungan dan kemudahan } \\
\text { yang boleh diterima oleh pentadbir sekolah }\end{array}$ & 15 item & 0.773 \\
\hline Jumlah Keseluruhan Item & 68 item & 0.826 \\
\hline
\end{tabular}

Dapatan kajian rintis menunjukkan bahawa kebolehpercayaan keseluruhan soal selidik adalah 0.832 manakala nilai alfa dimensi mengenai prosedur dan undangundang pendidikan menunjukkan nilai bacaan 0.785 ; kebolehan pentadbir membuat rujukan daripada sumber undang-undang pendidikan- 0.841 untuk latihan latihan dan kursus yang pernah dihadiri berkenaan akta dan undangundang pendidikan menunjukkan nilai kebolehpercayaan yang diperolehi ialah 0.773 manakala untuk tahap perlindungan dan kemudahan yang boleh diterima oleh pentadbir sekolah menunjukkan nilai kebolehpercayaan yang diperolehi ialah 0.826. Justeru, dapat dirumuskan bahawa nilai alfa melebihi nilai 0.60 seperti yang ditetapkan oleh Mitchell dan Jolley (2004) sesuai digunakan untuk kajian seterusnya.

\subsection{DAPATAN KAJIAN}

\subsection{Analisis Demografi Pentadbir Sekolah}

Maklumat latar belakang pentadbir merangkumi jantina, umur, lokasi sekolah, kelulusan akademik tertinggi, kategori perkhidmatan, gred jawatan, jawatan dan 
pengalaman. Analisis frekuensi demografi menunjukkan bahawa terdapat perbezaan yang ketara dalam taburan pentadbir sekolah mengikut jantina. Jumlah pentadbir sekolah rendah yang telah memulangkan soal selidik kajian ini ialah 87 orang. Analisis deskriptif tentang ciri demografi pentadbir sekolah ditunjukkan melalui Jadual 2.

Jadual 2 Taburan pentadbir mengikut demografi

\begin{tabular}{lcc}
\hline Pemboleh ubah & Kekerapan & Peratusan (\%) \\
\hline Jantina & 40 & 46 \\
Lelaki & 47 & 54 \\
Perempuan & & \\
Umur & 1 & 1.2 \\
30 hingga 35 tahun & 14 & 16.1 \\
36 hingga 40 tahun & 14 & 16.1 \\
41 hingga 45 tahun & 29 & 33.3 \\
46 hingga 50 tahun & 19 & 33.3 \\
50 ke atas & & \\
Lokasi Sekolah & 49 & 56.3 \\
Bandar & 38 & 43.7 \\
Luar Bandar & & \\
Gred Jawatan & 60 & 69.0 \\
DGA 32 & 10 & 11.5 \\
DGA 34 & 7 & 8.0. \\
DGA 38 & 10 & 11.5 \\
DG 41 & & \\
\hline
\end{tabular}

Berdasarkan Jadual 2, seramai 87 orang pentadbir sekolah telah memberi maklum balas, majoriti daripada responden adalah pentadbir perempuan iaitu seramai 47 orang dan 40 orang lagi adalah lelaki. Taburan mengikut peringkat umur pula mendapati 33.3 peratus pentadbir adalah dalam lingkungan umur 46 hingga 50 tahun. Manakala, 14 orang pentadbir atau 16.1 peratus lagi berada dalam lingkungan umur 36 hingga 40 tahun dan peringkat umur 41 hingga 45 tahun. Manakala hanya seorang pentadbir sahaja atau 1.2 peratus yang berada pada peringkat umur 30 hingga 35 tahun. Dari segi lokasi sekolah pula, dapatan menunjukkan seramai 49 orang pentadbir berkhidmat atau 56.3 peratus berkhidmat di sekolah yang terletak di kawasan bandar manakala seramai 38 orang pentadbir sekolah atau 43.7 peratus berkhidmat di sekolah kategori luar bandar. Jadual 2 di atas juga menunjukkan gred jawatan pentadbir sekolah. 
Dapatan kajian turut menunjukkan bahawa seramai 60 pentadbir atau 69 peratus adalah berada pada gred jawatan DGA32, 10 orang pentadbir atau 11.5 peratus berada pada gred DGA34 dan DG41. Manakala jumlah pentadbir yang berada dalam gred DGA38 adalah seramai tujuh orang pentadbir sahaja yang mewakili 8 peratus daripada keseluruhan responden kajian .

\subsection{Analisis Deskriptif Pentadbir Sekolah}

Berdasarkan Jadual 3, dapatan deskriptif berasaskan nilai skor min menunjukkan rumusan secara keseluruhan tentang pemahaman perundangan pendidikan dalam kalangan pentadbir sekolah rendah. Terdapat empat daripada enam objektif/persoalan kajian yang dikaji iaitu yang berkaitan dengan tahap pengetahuan dan kemahiran tentang undang-undang dan prosedur pendidikan; kekerapan pentadbir sekolah membuat rujukan tentang undang-undang pendidikan daripada sumber-sumber rujukan yang sesuai, latihan dan kursus yang diperolehi oleh pentadbir sekolah tentang undang-undang dan prosedur pendidikan, dan tahap perlindungan dan kemudahan perundangan yang boleh diperolehi oleh pentadbir sekolah.

Dalam mencari kepastian tentang pengetahuan pentadbir sekolah tentang ilmu pengetahuan serta kemahiran yang tinggi tentang undang-undang dan prosedur dalam bidang pendidikan, majoriti pentadbir mengatakan bahawa mereka sedar dan sering diberikan ilmu dan pengetahuan tentang undang-undang dan prosedur dalam bidang pendidikan iaitu nilai 4.14 berada pada tahap yang tinggi. Dapatan ini membuktikan bahawa pentadbir/pemimpin sekolah sememangnya telah menguasai elemen perundangan yang berkait dengan sistem pendidikan. Penelitian tentang kekerapan pentadbir sekolah membuat rujukan tentang undang-undang pendidikan daripada sumber-sumber rujukan yang sesuai. Secara keseluruhannya, jumlah purata skor min bagi tingkah laku merujuk dokumen yang berkait dengan undang-undang ialah pada nilai skor min 3.05 iaitu nilai yang menunjukkan tahap yang sederhana. Analisis data membuktikan bahawa pentadbir sekolah sentiasa cuba untuk mengelakkan institusi mereka daripada terlibat dalam kesalahan dan kecuaian yang membolehkan warga dan institusi sekolah dikenakan tindakan tatatertib. Oleh itu, pentadbir perlu sentiasa merujuk sumber undang-undang dan pekeliling setiap kali menjalankan tugas dan sebelum membuat keputusan tentang operasi dan perjalanan sekolah. 
Jadual 3 Rumusan dapatan kajian berdasarkan objektif kajian

\begin{tabular}{lcc}
\multicolumn{1}{c}{ Objektif Kajian } & Skor Min & Tahap \\
\hline $\begin{array}{l}\text { Pengetahuan dan kemahiran pentadbir sekolah } \\
\text { tentang undang-undang dan prosedur pendidikan. }\end{array}$ & 4.14 & Tinggi \\
$\begin{array}{l}\text { Kekerapan pentadbir sekolah membuat rujukan } \\
\text { tentang undang-undang pendidikan daripada } \\
\text { sumber-sumber rujukan yang sesuai. }\end{array}$ & 3.05 & Sederhana \\
$\begin{array}{l}\text { Latihan dan kursus pentadbir sekolah tentang } \\
\text { undang-undang dan prosedur pendidikan yang } \\
\text { secukupnya. }\end{array}$ & & Sederhana \\
$\begin{array}{l}\text { Tahap perlindungan dan kemudahan } \\
\text { perundangan yang boleh diperolehi oleh pentadbir } \\
\text { sekolah. }\end{array}$ & 3.93 & Tinggi \\
\hline Purata Keseluruhan Skor Min & & Sederhana \\
\hline
\end{tabular}

Analisis data tentang persoalan sama ada pentadbir sekolah mendapat latihan dan kursus tentang undang-undang dan prosedur pendidikan yang secukupnya. Secara keseluruhannya, jumlah purata skor min ialah 2.48, iaitu menunjukkan nilai yang berada pada tahap yang sederhana yang membuktikan bahawa ada pentadbir sekolah berpendapat mereka memerlukan pendedahan yang lebih mendalam berkait dengan kursus dan latihan perundangan terutamanya yang disediakan oleh pihak Kementerian Pelajaran Malaysia dan Jabatan Pelajaran Negeri. Manakala, analisis data tentang mengenalpasti tahap perlindungan dan kemudahan perundangan yang boleh diperolehi oleh pentadbir sekolah. Secara keseluruhannya, purata skor min bagi objektif kajian ini ialah 3.93 iaitu menunjukkan nilai yang berada pada tahap yang tinggi. Hal ini disebabkan majoriti setiap pentadbir sekolah merupakan ahli kesatuan guru yang memperjuangkan kebajikan para guru. Maka, mereka merasa selamat tentang tahap perlindungan dan kemudahan yang diberikan dianggap telah memadai buat mereka. Berdasarkan keempat-empat objektif kajian tersebut mendapati nilai purata skor min yang diperolehi ialah 3.40 iaitu menunjukkan nilai yang berada pada tahap yang sederhana. Keputusan ini menunjukkan tahap pemahaman dan kemahiran 
para pentadbir sekolah rendah tentang undang-undang, akta pendidikan, pekelilingpekeliling ikhtisas pendidikan, dan perintah-perintah Am kakitangan awam masih berada pada tahap sederhana.

\subsection{Pengujian Hipotesis}

Bagi mengenal pasti perbezaan tahap pengetahuan dan pemahaman tentang perundangan dalam pendidikan, analisis Ujian-t dan ANOVA Sehala telah digunakan dan dapatannya ditunjukkan melalui Jadual 4 dan Jadual 5.

Jadual 4 Ujian-t berdasarkan jantina pentadbir

\begin{tabular}{lllll}
\hline Sumber & N & Min & F & Sig \\
\hline Lelaki & 40 & 4.150 & 0.343 & 0.559 \\
Wanita & 47 & 4.085 & & \\
& & & & \\
${ }^{*} p<.05 ; \mathrm{N}=87$. & & &
\end{tabular}

Hasil kajian menunjukkan bahawa tidak terdapat perbezaan yang signifikan berdasarkan pengetahuan perundangan pentadbir sekolah berdasarkan faktor jantina $(\mathrm{F}=0.343 ; \mathrm{Sig}=0.559)$ pada aras $p<0.05$. Oleh itu, keputusan ini menunjukkan tidak terdapat perbezaan yang bererti dalam aspek pengetahuan dalam perundangan pendidikan dalam kalangan pentadbir lelaki dengan pentadbir wanita.

Jadual 5 Ujian Analisis Varian Sehala Pengetahuan Perundangan Berdasarkan Jawatan Pentadbir Sekolah

\begin{tabular}{cccccc}
\hline & JKD & DK & MKD & F & Sig. \\
\hline $\begin{array}{c}\text { Antara } \\
\text { Kumpulan }\end{array}$ & 3.259 & 4 & .815 & 3.094 & $.020^{*}$ \\
Dalam Kumpulan & 21.592 & 82 & .263 & & \\
Jumlah & 24.851 & 86 & & & \\
\hline${ }^{*} p<.05 ; \mathrm{N}=87$ & & & & &
\end{tabular}


Dari segi jawatan pula, hasil analisis ANOVA Sehala menunjukkan terdapat perbezaan yang signifikan tentang tahap pengetahuan dalam perundangan terhadap jawatan pentadbir $(\mathrm{F}=3.094 ; \mathrm{Sig}=0.02)$. Oleh itu, keputusan ini menunjukkan terdapat perbezaan yang bererti dalam aspek pengetahuan dalam perundangan pendidikan berdasarkan kepada jawatan pentadbir di sekolah rendah. Seterusnya, ujian Post Hoc Scheffe dilaksanakan untuk mengenal pasti perbezaan skor min aspek pengetahuan perundangan dalam pendidikan dan dapatannya diperlihatkan melalui Jadual 6 di bawah.

Jadual 6 Ujian Post Hoc Scheffe pengetahuan perundangan berdasarkan jawatan

\begin{tabular}{lllcc}
\hline $\begin{array}{l}\text { Pemboleh } \\
\text { ubah }\end{array}$ & $\begin{array}{l}\text { Jawatan Pentadbir } \\
(\mathbf{I})\end{array}$ & $\begin{array}{l}\text { Jawatan Pentadbir } \\
(\mathbf{I}-\mathbf{J})\end{array}$ & $\begin{array}{l}\text { Perbezaan } \\
\text { Skor Min }\end{array}$ & $\begin{array}{c}\text { Nilai } \\
\text { Signifikan }\end{array}$ \\
\hline Pengetahuan & Guru Besar & GPK (Pentadbiran) & .045 & .797 \\
Perundangan & GPK (HEM) & .053 & .527 \\
Pendidikan & GPK (Koko) & .322 & .025 \\
& GPK (Petang) & .451 & .014 \\
\hline
\end{tabular}

${ }^{*} p<.05 ; \mathrm{N}=87$

Secara jelas, terdapat perbezaan skor min secara signifikan pada aras $p<0.05$ antara antara pasangan jawatan guru besar dengan Guru Penolong Kanan (Kokurikulum ) dengan nilai perbezaan skor min sebanyak 0.322 dan pasangan jawatan guru besar dengan Guru Penolong Kanan (Petang) dengan nilai perbezaan skor min sebanyak 0.451. Justeru itu, dapat dirumuskan bahawa perbezaan yang signifikan tentang pengetahuan dan kemahiran perundangan dalam pendidikan adalah di antara antara pasangan guru besar dengan Guru Penolong Kanan (Kokurikulum) dengan Guru Penolong Kanan (Petang) sahaja. Ini mungkin berlaku kerana Guru Penolong Kanan (Hal Ehwal Murid) dan Guru Penolong Kanan (Petang) dapat dianggap sebagai pentadbir pendidikan novis yang baru dilantik untuk mengurus dan memimpin sekolah.

\subsection{PERBINGANGAN DAN RUMUSAN}

Hasil kajian mendapati bahawa pentadbir sekolah mempunyai ilmu pengetahuan serta kemahiran tentang undang-undang dan prosedur dalam bidang pendidikan. Hal ini dibuktikan melalui jumlah purata skor min yang memperlihatkan nilai skor 
min yang tinggi iaitu nilai 4.14 yang berada pada tahap yang tinggi. Hal ini berlaku kerana pentadbir sekolah telah didedahkan dengan kursus-kursus tentang undangundang dalam pendidikan yang telah diserapkan dalam kursus-kursus Pengurusan Sekolah kendalian Institut Aminuddin Baki (IAB) dan Jabatan Pelajaran Negeri (JPN). Sehubungan itu, pembangunan kapasiti kepimpinan sekolah seperti JPN dan IAB perlu sentiasa melengkapkan pemimpin dengan pengetahuan undangundang yang sesuai supaya amalan yang betul dari perspektif undang-undang boleh mengurangkan risiko didakwa terhadap pihak sekolah. Di samping itu, kedua institusi dim atas perlu turut memantau tahap pengetahuan pentadbir sekolah kerana ditakuti pentadbir yang dilantik belum mahir dalam aspek perundangan pendidikan. Pentadbir yang tidak mahir dalam aspek perundangan pendidikan akan menyukarkan pihak sekolah melaksanakan operasi harian sekolah. Pihak pentadbiran sekolah juga perlu menerokai ruang bidang tugasan dan tanggungjawab yang digalas dan diamanahkan agar dapat melaksanakan kerja dengan penuh komitmen berdasarkan garis panduan dan pengurusan organisasi (Mohd Ismail Othman, 2004; Hall \& Strike, 1984).

Dapatan kajian juga turut membuktikan bahawa pentadbir sekolah turut kerapkali dan sentiasa merujuk kepada sumber undang-undang dan pekeliling yang diedarkan oleh Kementerian Pelajaran Malaysia ketika menjalankan tugas serta membuat keputusan. Hal ini kerana besar kemungkinan pentadbir sekolah rendah mempunyai koleksi sumber rujukan yang lengkap tentang prosedur dan tatacara pengurusan sekolah di pejabat mereka untuk dijadikan panduan dan rujukan dalam proses mengurus sekolah khususnya berkait dengan operasi dan perancangan sekolah. Sehubungan dengan itu, sumber-sumber perundangan pendidikan seperti Surat Pekeliling Ikhtisas, Akta-akta Pendidikan, Perintahperintah Am telah dijadikan panduan penting ketika memimpin dan mengurus sekolah agar tidak terkeluar daripada garis panduan yang telah ditetapkan oleh Kementerian Pelajaran Malaysia.

Hasil kajian ini juga menjelaskan bahawa majoriti pentadbir sekolah rendah berpendapat bahawa mereka masih kurang mendapat pendedahan berhubung kursus dan latihan perundangan terutamanya yang disediakan oleh pihak Kementerian Pelajaran Malaysia, Jabatan Pendidikan Negeri malah Pejabat Pendidikan Daerah dan institusi-institusi berkaitan seperti Institut Aminuddin Baki atau universiti tempatan yang menawarkan kursus berkaitan perundangan dalam pendidikan. Bagi sarjana perundangan dalam pendidikan (Rossow, 1990; Steward, 2005; Steward, 1998; Reglin 1990), program pendedahan tentang 
perundangan di sekolah haruslah bermula dalam program persediaan guru pelatih dan diperluaskan dalam program-program persediaan pentadbir sekolah, serta seharusnya menjadi silibus yang wajib semasa mengikuti kursus dalam perkhidmatan yang dilaksanakan kepada para pendidik di semua peringkat.

Hasil kajian yang meneliti perlindungan kepada pentadbir sekolah oleh pihak penggubal dasar sekira berlaku tuntutan atau risiko dakwaan oleh pihak mahkamah juga mendapati majoriti pentadbir sekolah rendah berpendapat bahawa mereka akan dilindungi oleh kesatuan guru. Namun begitu, pentadbir juga sedar bahawa segala tindakan yang memberi kesan kepada pelajar atau guru akan ditanggung sendiri oleh mereka malah mereka perlu bersedia malah berhati-hati untuk mengelakkan diri daripada didakwa oleh pihak mahkamah.

\subsection{Cadangan}

Dalam usaha menghasilkan pentadbir sekolah yang mahir dalam bidang perundangan dalam pendidikan, maka beberapa saranan dan cadangan dikemukakan untuk meningkatkan kemampuan pentadbir sekolah dan mencegah daripada dikenakan dakwaan. Saranan tersebut ialah:

(a) Kursus yang berkaitan dengan etika professional perlu diperbanyakkan bagi memberi ruang kepada pentadbir sekolah untuk meningkatkan kualiti pengetahuan dalam bidang pengurusan, perundangan dan perkembangan etika profesion.

(b) Memandangkan peranan dan tugas Guru Besar dan Guru Penolong Kanan sangat penting untuk meningkatan keberkesanan sekolah, maka dicadangkan agar mereka diberi latihan persediaan kepengetuaan dan satu sistem sokongan profesional (mentor) yang formal. Mengikut cadangan Kementerian Pelajaran Malaysia, mereka yang dikenal pasti layak untuk memegang jawatan Guru Besar akan diberi latihan kepengetuaan sebelum menjawat jawatan pentadbir sekolah. Ini kerana, masih lagi kurang sistem sokongan profesional yang formal untuk membantu pentadbir-pentadbir sekolah yang novis. 
(c) Disarankan juga supaya diwujudkan suatu sistem mentor yang formal agar Guru Besar yang lebih senior serta pegawai-pegawai yang berkemahiran dapat membantu rakan-rakan pentadbir yang masih baru dalam bidang pengurusan sekolah. Permuafakatan formal sebegini akan berupaya meningkatkan kualiti pengurusan di sekolah. Di samping itu, latihanlatihan yang direka bentuk seharusnya tidak tertumpu pada bidang teori yang bersifat cookbook recipes semata-mata, sebaliknya perlu menggabungjalinkan teori, penyelidikan, dan amalan yang berasaskan realiti.

(d) Institusi yang menawarkan kursus perguruan dan universiti tempatan yang menganjurkan program untuk bakal pendidik seharusnya menawarkan kursus yang ada kaitan dengan peraturan dan perundangan pendidikan. Ini amat penting sekali kerana guru-guru sentiasa terdedah kepada perkaraperkara yang berisiko tinggi di sekolah sekiranya mereka tidak memahami peraturan dan undang-undang yang berkaitan dengan pendidikan. Guru juga ditugaskan juga dibebani dengan tanggungjawab yang amat berat bagi menjaga dan mendidik anak-anak secara sah.

\subsection{KESIMPULAN}

Pemimpin sekolah dan guru kini mempunyai tanggungjawab yang berat daripada segi perundangan kesan berdasarkan tanggungjawab dan kewajipan perundangan terhadap pelajar dengan baik. Pengurusan sekolah yang pro-aktif dan sedia menghadapi cabaran perundangan semasa dijangka dapat menguruskan sekolah dengan penuh yakin malah segala keputusan dan tindakan yang diambil berdasarkan peraturan dan prinsip perundangan yang jelas dapat membantu pemimpin sekolah mengurangkan risiko dakwaan mahkamah.

\section{RUJUKAN}

Abdul Aziz Hussin. 2002) Undang undang Yang Mengenai Kelakuan dan Tatatertib Penjawat Awam. Kuala Lumpur : Dewan Bahasa dan Pustaka.

Dunklee, D. 1985. An Assessment of Knowledge About Tort Liability Law As Possessed by Selected Public School Teachers and Principals. Doctoral dissertation, Kansas State University. 
Fisher, L., Schimmel, D., \& Kelly, C. 1981. Teachers and the Law. New York: Longman.

Fischer, L., Schimmel, D., \& Stellman, L. 2003. Teachers and the Law. Boston: Allyn \& Bacon.

Haller, E., \& Strike, K. 1986. An Introduction to Educational Administration: Social, Legal and Ethical Perspectives. New York: Longman.

Kementerian Pelajaran Malaysia. 1996. Pelaksanaan Kuasa Disiplin dan Hukuman di Sekolah. Surat Pekeliling Ikhtisas Bil. 4/1996. Bertarikh 03 September.

Kementerian Pelajaran Malaysia. 2003. Kuasa Guru Merotan Murid. Surat Pekeliling Ikhtisas Bil. 7/2003. Bertarikh 29 Oktober.

Kementerian Pelajaran Malaysia. 1998. Penggunaan Budi Bicara Ketika Mengambil Tindakan. Surat Pekeliling Ikhtisas Bil. 18/1998. Bertarikh 02 September.

Kementerian Pelajaran Malaysia. 1999. Larangan Terhadap Penglibatan Pegawai Perkhidmatan Pendidikan, Staf Sokongan dan Murid Sekolah Dalam Kegiatan Politik Anti Kerajaan. Surat Pekeliling Ikhtisas Bil. 5/1999. Bertarikh 11 Mei.

Kementerian Pelajaran Malaysia. 1988. Keselamatan Diri Pelajar Di Sekolah sekolah. Surat Pekeliling Ikhtisas Bil. 8/1988. Bertarikh 01 Mac.

Kementerian Pelajaran Malaysia. 1989. Garis Panduan Dari Segi Pencegahan Kebakaran Bagi Domitori dan Asrama. Surat Pekeliling Ikhtisas Bil. 12/1989. Bertarikh 09 Disember.

Kementerian Pelajaran Malaysia. 1991. Pelaporan Kejadian Tidak Diingini Di Sekolah. Surat Pekeliling Ikhtisas Bil. 4/1991. Bertarikh 16 Mei.

Kementerian Pelajaran Malaysia. 1993. Lapor Kepada Polis Salahlaku Yang Berbentuk Jenayah. Surat Pekeliling Ikhtisas Bil. 3/1993. Bertarikh 15 Februari.

Kementerian Pelajaran Malaysia. (1995). Keselamatan Diri Pelajar Semasa Pengajaran Pendidikan Jasmani dan Kesihatan Serta Kegiatan Kokurikulum dan Sukan Di Dalam dan Di Luar Kawasan Sekolah. Surat Pekeliling Ikhtisas Bil. 1/1995. Bertarikh 06 April.

Kementerian Pelajaran Malaysia. 1995. Tatacara Mengenakan Tindakan dan Hukuman Terhadap Pelajar pelajar Sekolah. Surat Pekeliling Ikhtisas Bil. 7/1995. Bertarikh 11 Oktober.

Kigin, R. 1983. Recent Graduates Have Definite Ideas on How to Improve Teacher Education Programs. The Teacher Evaluator. 59: 168-172.

Mitchell, M., \& Jolley, J. 2004. Research Design Explained. New York: Thompson Learning.

Minor, J. \& Minor, V. 1991. Risk management in Schools: A Guide To Minimizing Liability. Newbury Park, CA: Corwin.

Mohd. Ismail Othman. 2008. Undang undang Untuk Pengetua छ Guru Besar. Kuala Lumpur : PTS.

Normzali Abdul Rahim. 2004. Kepengetuaan dan Undang-undang: Isu dan Cabaran. Dalam Rahimah Haji Ahmad \& Tie Fatt Hee (eds.). Kepengetuaan dan Kepemimpinan Sekolah: Perspektif Pengamal. Kuala Lumpur: Institut Pengajian Kepengetuaan, Universiti Malaya.

Pell, S. 1994. Pre-service Teachers' Lack of Knowledge of Education Law: Ignorance is No Excuse. Illinois School Law Quarterly. 14(4): 12-20.

Permuth, S. 1998. The Principal and the Issue of Negligence. NASSP Buletin. 82: 42-47.

Ramsay, I. \& Shorten A. 1996. Education and the Law. Butterworth: Sydney.

Reglin, G. 1990. Public School Educators' Knowledge of Selected Supreme Court Decisions Affecting Daily Public School Operations. Research in Rural Education. 7(1): 17-22.

Rossow, L. F. 1990. The Principalship, Dimensions In Instructional Leadership. New Jersey: Prentice-Hall.

Sametz, L., McLoughlin, C., \& Streib, V. 1983. Legal Education for Pre-Service Teachers: Basics or Remediation? Journal of Teacher Education. 34: 10-12.

Schimmel, D., Fischer, L., \& Stellman, L. 2008. School Law: What Every Educators Should Know. Boston: Allyn \& Bacon. 
Stewart, D. 2005. The Place of Law in the Leadership and Management of Schools. Education and the Law. 17(4): 127-136.

Stewart, D. 1998. Legalisation of Education: Implications for Principals' Professional Knowledge. Journal of Educational Administration. 36(2): 129-145.

Sorenson, G. \& Chapman, D. 1985. School Compliance with Federal Law Concerning the Release of Student Records. Educational Evaluation and Policy Analysis. 7: 9 -18.

Tie Fatt Hee. 2002. Undang undang dalam Pendidikan. Petaling Jaya: Fajar Bakti.

Tie Fatt Hee. 2004. Liabiliti Dalam Pengurusan Pendidikan. Kuala Lumpur: Utusan.

Waring, A. \& Glendon, A. 1998. Managing Risk. London: International Thomson Business Press

Williams, P. (1994). Saying Things About Students: The Legal Implications for Educators. The Practising Administrator. 16(4): 4-6. 